Article

\title{
Effect of Sows Gestational Methionine/Lysine Ratio on Maternal and Placental Hydrogen Sulfide Production
}

\author{
Jie Peng ${ }^{1,2, \dagger}$, Mao Xia ${ }^{2, \dagger}$, Jia Xiong ${ }^{2}$, Chenbin Cui ${ }^{2}$, Ningning Huang ${ }^{2}$, Yuanfei Zhou ${ }^{2} \mathbb{}$, \\ Hongkui Wei ${ }^{2}$ and Jian Peng ${ }^{2,3, *}$ \\ 1 Innovative Institute of Animal Healthy Breeding, College of Animal Sciences and Technology, \\ Zhongkai University of Agriculture and Engineering, Guangzhou 510225, China; pengjie@zhku.edu.cn \\ 2 Department of Animal Nutrition and Feed Science, College of Animal Science and Technology, \\ Huazhong Agricultural University, Wuhan 430070, China; xiamao_1992@163.com (M.X.); \\ xj511845341@126.com (J.X.); cuichenbin@webmail.hzau.edu.cn (C.C.); ninghuang2020@163.com (N.H.); \\ zhouyuanfei@mail.hzau.edu.cn (Y.Z.); weihongkui@mail.hzau.edu.cn (H.W.) \\ 3 The Cooperative Innovation Center for Sustainable Pig Production, Wuhan 430070, China \\ * Correspondence: pengjian@mail.hzau.edu.cn \\ + Both authors contributed equally.
}

Received: 5 December 2019; Accepted: 27 January 2020; Published: 5 February 2020

check for updates

Simple Summary: Hydrogen sulfide $\left(\mathrm{H}_{2} \mathrm{~S}\right)$ is an important second messenger, which has been implicated in regulating placental angiogenesis. Our findings revealed that gestational dietary methionine could affect maternal and placental $\mathrm{H}_{2} \mathrm{~S}$ concentrations. With the increase of dietary methionine, maternal plasma and placental $\mathrm{H}_{2} \mathrm{~S}$ concentrations changed quadratically, which was consistent with placental vascular density and reproductive performance. The decrease in $\mathrm{H}_{2} \mathrm{~S}$ production caused by an increase in dietary methionine was likely to be the cause for the increase in the rate of low birth weight piglets and needs further study.

\begin{abstract}
The placenta is a unique bond between the mother and the fetus during pregnancy, and a proper placental angiogenesis is vital for fetal development. $\mathrm{H}_{2} \mathrm{~S}$ is an endogenous stimulator of angiogenesis that is mainly produced by the methionine transsulfurationpathway. The goal of this study was to evaluate the effect of gestational dietary methionine on maternal and placental $\mathrm{H}_{2} \mathrm{~S}$ production in sows. Multiparous sows (LargexWhite; third parity; $n=65$ ) were randomly allocated into five groups, with feed diets comprisingstandardized ileal digestible methionine/lysine (Met/Lys) ratios of 0.27 (nutrient requirements of swine (NRC); 2012 level), 0.32, 0.37, 0.42, and 0.47, respectively. The litter size and weight at birth were measured and recorded. Maternal blood samples were obtained at embryonic day (E) E40 d, E90 d, and E114 d of gestation. The placental samples were collected at parturition. The results showed that maternal plasma $\mathrm{H}_{2} \mathrm{~S}$ concentration was not affected at $\mathrm{E} 40 \mathrm{~d}$. However, the maternal plasma $\mathrm{H}_{2} \mathrm{~S}$ concentration changed quadratically with the dietary Met/Lys ratio at E90 d $(p<0.01)$ and E114 $\mathrm{d}(p=0.03)$. The maximum maternal plasma $\mathrm{H}_{2} \mathrm{~S}$ concentration was at the dietary Met/Lys ratio of 0.37 . Meanwhile, maternal plasma $\mathrm{H}_{2} \mathrm{~S}$ concentration was positively correlated with piglets born alive $(p<0.01)$ and litter weight $(p<0.01)$. Consistent with the maternal plasma, the placental $\mathrm{H}_{2} \mathrm{~S}$ concentration also changed quadratically with the dietary Met/Lys ratio $(p=0.03)$; the Met/Lys ratio of 0.37 showed the maximum $\mathrm{H}_{2} \mathrm{~S}$ concentration. In conclusion, our findings revealed that the gestational dietary Met/Lys ratio could affect maternal and placental $\mathrm{H}_{2} \mathrm{~S}$ concentrations, which may be an important molecular mechanism affecting placental angiogenesis and piglet development.
\end{abstract}

Keywords: hydrogen sulfide; reproductive performance; pregnant sows; methionine; placental angiogenesis 


\section{Introduction}

Methionine (Met) is an essential amino acid in the diets of pigs [1,2]. In addition to being a substrate for protein synthesis, Met is also a methyldonor in DNA, RNA, and protein methylation. This methylation reaction results in epigenetic changes in gene expression and protein function during embryonic development [3,4]. Functional amino acids are important for the development of the pig placenta [5]. In our previous work, we demonstrated that an appropriate increase in the methionine/lysine (Met/Lys) ratio in a sow's diet had a positive effect on the sow'splacental vascular density and on the birth weight of the piglets [6]. However, the underlying mechanism by which Met promotes placental angiogenesis and fetal development is unclear.

Hydrogen sulfide $\left(\mathrm{H}_{2} \mathrm{~S}\right)$ is a ubiquitous signaling molecule with important functions in many mammalian cells and tissues and is now considered to be the third gas-phase signaling molecule, in addition to carbon monoxide (CO) and nitric oxide (NO) [7-9]. Endogenous $\mathrm{H}_{2} \mathrm{~S}$ is mainly produced by Met and the cysteine transsulfuration pathway (TSP), via the direct enzymatic action of cystathionine- $\gamma$-lyase (CGL) and cystathionine- $\beta$-synthase (CBS) $[10,11]$. Studies in humans have found that preeclampsia and intrauterine growth retardation (IUGR) correspond to a significant reduction in placental $\mathrm{H}_{2} \mathrm{~S}$ production, placental angiogenesis, and blood flow velocity [12,13]. However, exogenous $\mathrm{H}_{2} \mathrm{~S}$ donors significantly attenuated placental vascular dysplasia and IUGR, caused by CGL inhibition [14]. In vitro studies have also shown that $\mathrm{H}_{2} \mathrm{~S}$ produced by trophoblast cells can promote angiogenesis in placental artery endothelial cells [15]. However, there were no reports of the regulation of $\mathrm{H}_{2} \mathrm{~S}$ production in sow plasma and placenta. The goal of the current study was to investigate the role of the gestational methionine/lysine ratio on maternal and placental $\mathrm{H}_{2} \mathrm{~S}$ production, both in vivo and in vitro.

\section{Materials and Methods}

\subsection{Animals, Diets and Management}

The experimental design and the dietary formula were described previously [6]. In this study, multiparous sows (Large $\times$ White; third parity; $n=65$ ) were randomly allocated into five groups and fed diets with standardized ileal digestible methionine/lysine (Met/Lys) ratios of 0.27 (nutrient requirements of swine (NRC); 2012 level), 0.32, 0.37, 0.42, and 0.47 respectively. The diet was maintained at constant levels of Lys (average SID Lys $0.71 \%$ ); the ingredients and nutrient compositions of the experimentaldiets are listed in Table S1. Sows were fed a gestational dietary $2.0 \mathrm{~kg} /$ day (from embryonic day E0 d to E3 d), $2.8 \mathrm{~kg} /$ day (E4 d to E30 d), $2.3 \mathrm{~kg} /$ day (E31 d to E90 d), and $2.9 \mathrm{~kg} /$ day (E91 d to farrowing). All sows were moved to individual farrowing crates with stalls at E90 d. The experimental protocol was approved by the Institutional Animal Ethics Committee of Huazhong Agricultural University (Ethics Code: HZAU SW-2016-014).

\subsection{Recording and Sampling}

The sample collection of blood and placenta was described previously [6]. Twelve sows by group were selected for blood sampling, and eight sows of each group were selected for placenta sampling. The litter size, the piglets born alive, the litter weight, and the average pig birth weight of each litter were recorded within $24 \mathrm{~h}$ after farrowing.

\subsection{Preparation of Placenta Homogenate}

The placenta was selected based on the average pig birth weight \pm one standard deviation of each group. A total of $100 \mathrm{mg}$ of placental tissue was separated and ground to a fine powder using a porcelain mortar and pestle, chilled with liquid nitrogen. Next, $10 \%$ of the tissue homogenate was made with $100 \mathrm{mM}$ of ice cold $\mathrm{KH}_{2} \mathrm{PO}_{4}$ buffer ( $\mathrm{pH}$ 7.4) and was centrifuged for $5 \mathrm{~min}$ at 13,000 rpm. The supernatant wasused for $\mathrm{H}_{2} \mathrm{~S}$ content and production assay. The protein concentration was determined by the bicinchoninic acid (BCA) protein assay kit (Beyotime, Shanghai, China). 


\subsection{Cell Culture and Treatment}

Porcine iliac artery endothelial cells (PIEC) were obtained from the cell bank of the Chinese Academy of Sciences (Shanghai, China), cultured in Roswell Park memorial institute (RPMI) 1640 medium (Gibco, San Diego, CA, USA), and supplemented with $10 \%$ fetal bovine serum (FBS, Gibco, San Diego, CA, USA) and $1 \%$ penicillin/streptomycin solution (Sigma, St. Louis, MO, USA) at $37{ }^{\circ} \mathrm{C}$ in a $5 \% \mathrm{CO}_{2}$ incubator. Before the Met treatment, the PIEC cells were seeded in a 12-well plate $\left(2 \times 10^{5}\right.$ cells/well); $80 \%$ confluent PIEC cells were placed in serum-free basic medium for $18 \mathrm{~h}$, followed by Met-free RPMI 1640 medium for another $6 \mathrm{~h}$, then treated with different concentrations of Met $(0,50,200,500$, and $1000 \mu \mathrm{M})$ for $24 \mathrm{~h}$ $(n=4)$. The supernatant culture medium was collected for $\mathrm{H}_{2} \mathrm{~S}$ content assay.

\section{5. $\mathrm{H}_{2} \mathrm{~S}$ Measurement}

In this study, the $\mathrm{H}_{2} \mathrm{~S}$ levels were measured through the formation of methylene blue $[16,17]$. For the plasma, $100 \mu \mathrm{L}$ samples were mixed with $400 \mu \mathrm{L}$ of $100 \mathrm{mM} \mathrm{KH}_{2} \mathrm{PO}_{4}$ buffer (pH 7.4) and 250 $\mu \mathrm{L}$ of $1 \%(\mathrm{w} / \mathrm{v})$ zinc acetate; for the culture medium and placental tissue homogenate, $500 \mu \mathrm{L}$ samples were mixed with $250 \mu \mathrm{L}$ of $1 \%(\mathrm{w} / \mathrm{v})$ zinc acetate. The reaction mixture was incubated at $37^{\circ} \mathrm{C}$ for $2.5 \mathrm{~h}$. The protein content in the samples was removed by adding $10 \%$ trichloroacetic acid $(250 \mu \mathrm{L})$ to the reaction mixture, which was pelleted by centrifugation. The supernatant was then mixed with $100 \mu \mathrm{L}$ of $N$-dimethyl-p-phenylenediamine sulfate $\left(20 \mathrm{mM}\right.$ in $7.2 \mathrm{M} \mathrm{HCl}$ ) and $100 \mu \mathrm{L}$ of $\mathrm{FeCl}_{3}(30 \mathrm{mM}$ in 1.2 $\mathrm{M} \mathrm{HCl}$ ) in a test tube. The mixture was incubated at room temperature for $15 \mathrm{~min}$. The absorbance of the resulting solution was measured at $670 \mathrm{~nm}$ in a 96-well plate with a microplate reader. The $\mathrm{H}_{2} \mathrm{~S}$ concentration was calculated using a standard (NaHS) calibration curve $(0.04,0.2,0.4,2,4,20$, and $40 \mu \mathrm{M})$ (Aladdin, Shanghai, China).

\subsection{Statistical Analyses}

Statistical analysis was performed using the SAS statistical package (v 8.2; SAS Inst. Inc., Cary, NC, USA). A one-way analysis of variance (ANOVA) followed by a least-significant-difference (LSD) post-hoc test was conducted to explore the impact of the gestational dietary Met/lysine ratio on maternal plasma and placenta $\mathrm{H}_{2} \mathrm{~S}$ concentrations, as shown in Figures 1-3, where $p<0.05$ was considered to indicate statistical significance. Regression analyses were performed to evaluate the quadratic effects of dietary Met/Lys ratio and $\mathrm{H}_{2} \mathrm{~S}$ concentration, as shown in Figures 1 and 2; the linear effects of dietary Met/Lys ratio and $\mathrm{H}_{2} \mathrm{~S}$ concentration are shown in Figure 4. Spearman correlations were used to determine the association between the dietary Met/Lys ratio and the piglets born alive, the litter weight of those born alive, and the average pig birth weight; see Figure 4. Data in all the Figures are expressed as mean \pm standard errors of the mean (SEM).

A

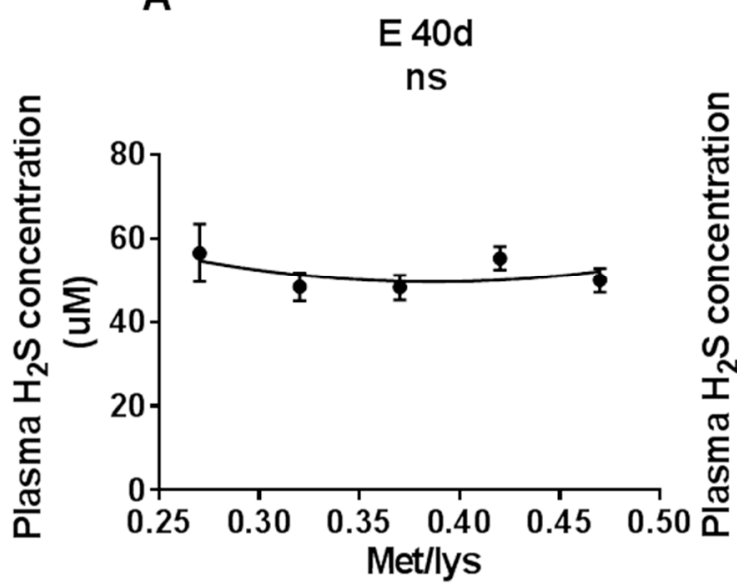

B

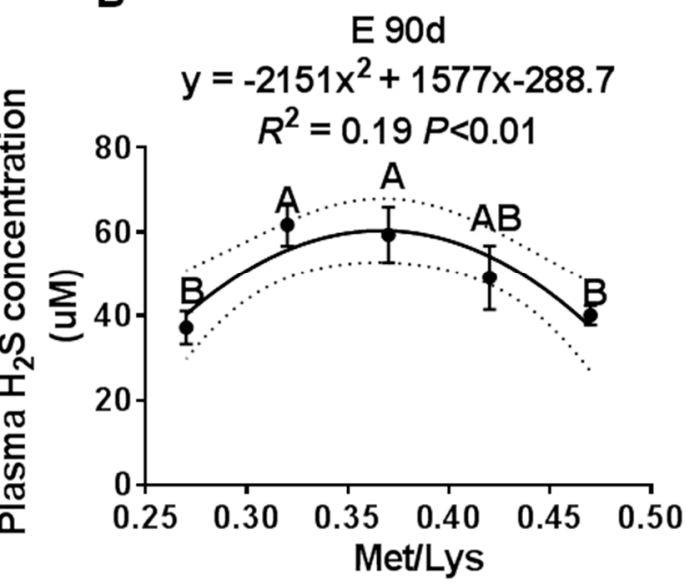

Figure 1. Cont. 


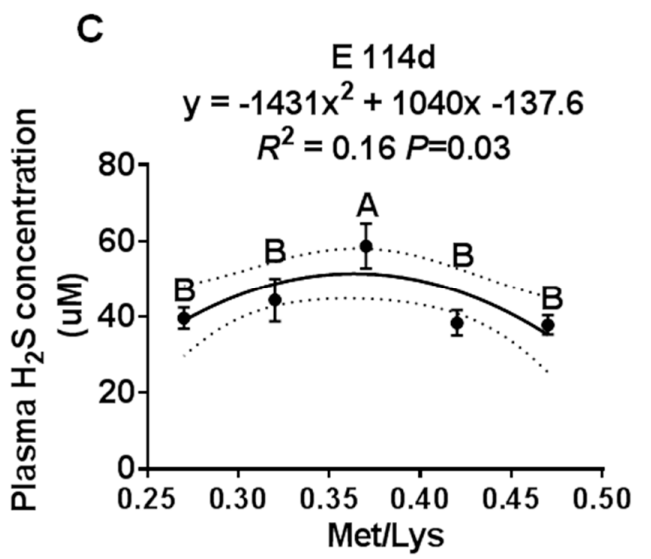

Figure 1. The effect of the gestational dietary Met/lysine ratio on maternal plasma hydrogen sulfide $\left(\mathrm{H}_{2} \mathrm{~S}\right)$ concentration at E40, E90, and E114: (A) maternal plasma $\mathrm{H}_{2} \mathrm{~S}$ concentration at E40 d, (B) maternal plasma $\mathrm{H}_{2} \mathrm{~S}$ concentration at $\mathrm{E} 90 \mathrm{~d}$, and (C) maternal plasma $\mathrm{H}_{2} \mathrm{~S}$ concentration at E114 d, $n=8-12 /$ group.

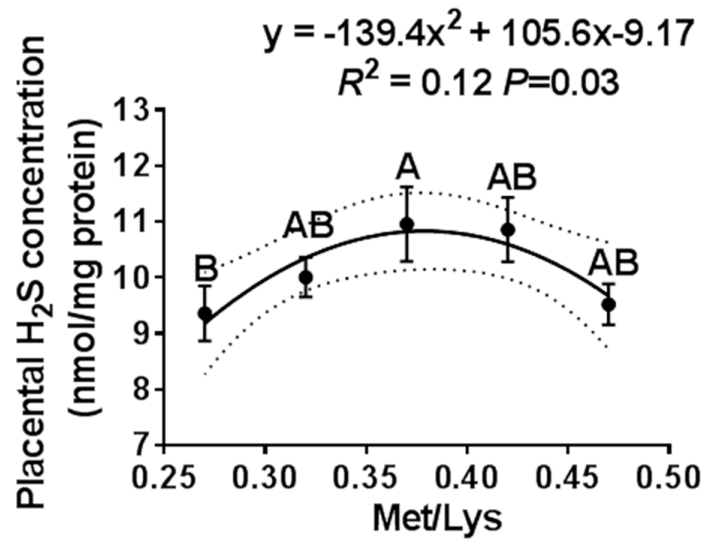

Figure 2. The effect of the gestational dietary Met/lysine ratio on placental $\mathrm{H}_{2} \mathrm{~S}$ concentration. Met/Lys ratios 0.27, $n=12$; Met/Lys ratios 0.32, $n=14 ;$ Met/Lys ratios 0.37, $n=11$; Met/Lys ratios 0.42, $n=11$; and Met/Lys ratios $0.47, n=11$.

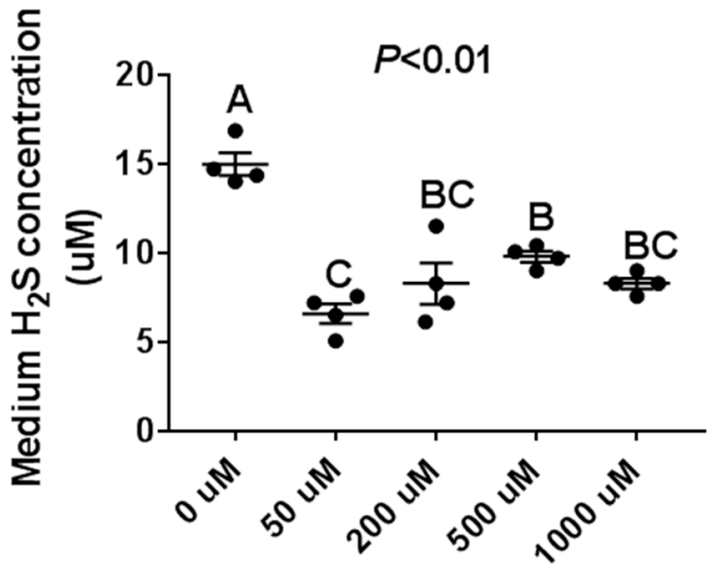

\section{Met concentration}

Figure 3. The effect of the Met treatment on porcine iliac artery endothelial cells (PIEC) $\mathrm{H}_{2} \mathrm{~S}$ production. The PIEC cells were seeded in a 12-well cell plate. After $80 \%$ confluence, the PIEC cells were placed in a serum-free medium for $18 \mathrm{~h}$, followed by a Met-free RPMI 1640 medium for another $6 \mathrm{~h}$, then treated with Met for $24 \mathrm{~h}$. The supernatant culture medium was collected for $\mathrm{H}_{2} \mathrm{~S}$ assay, $n=4$ /group. 
A

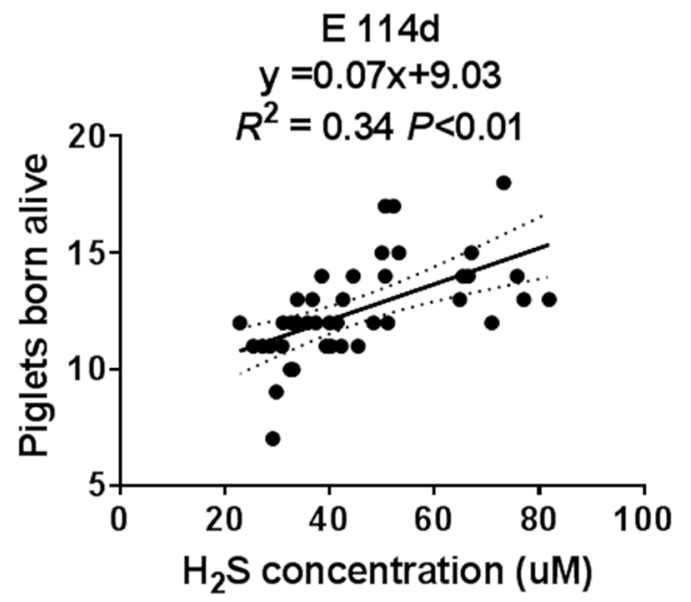

B

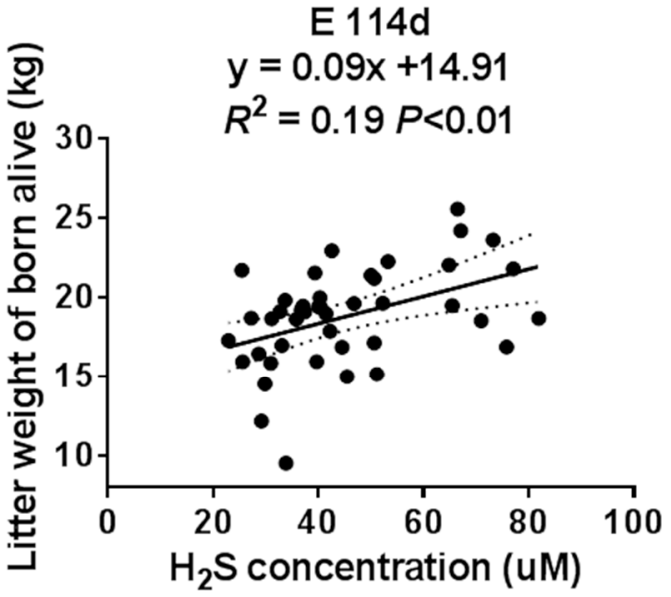

E 114d

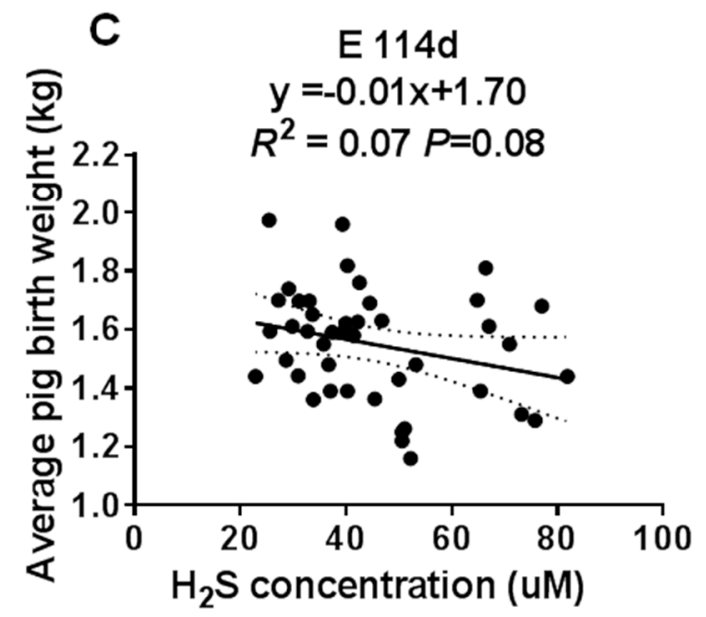

Figure 4. The correlation analysis of the maternal plasma $\mathrm{H}_{2} \mathrm{~S}$ concentration at E114d and the sow's reproductive performance. (A) Piglets born alive. (B) Litter weight of piglets born alive. (C) Average pig birth weight. Met/Lys ratios 0.27, $n=8$; Met/Lys ratios 0.32, $n=9$; Met/Lys ratios 0.37, $n=10$; Met/Lys ratios 0.42, $n=7$; Met/Lys ratios 0.47, $n=7$.

\section{Results}

\subsection{The Gestational Dietary Met/Lys Ratio Affected Maternal Plasma $\mathrm{H}_{2} \mathrm{~S}$ Concentration}

To study the effect of the gestation dietary Met/Lys ratio on maternal plasma $\mathrm{H}_{2} \mathrm{~S}$ concentration, we collected maternal plasma at different stages of pregnancy. We found that by E40 $\mathrm{d}$, increasing the Met/Lys ratio in the diet had no effect on the maternal plasma $\mathrm{H}_{2} \mathrm{~S}$ concentration, as shown in Figure 1A. However, at E90 d and E114 d, the maternal plasma $\mathrm{H}_{2} \mathrm{~S}$ concentration changed quadratically, with an increase in the dietary Met/Lys ratio, as shown in Figure 1B,C. According to the quadratic polynomial regression equation, at E90 $\mathrm{d}\left(\mathrm{y}=-2151 \mathrm{x}^{2}+1577 \mathrm{x}-288.7, \mathrm{R}^{2}=0.19, p<0.01\right)$ and at E114 $\mathrm{d}\left(\mathrm{y}=-1431 \mathrm{x}^{2}+1040 \mathrm{x}-137.6, \mathrm{R}^{2}=0.16, p=0.03\right)$, the maximum maternal plasma $\mathrm{H}_{2} \mathrm{~S}$ concentration was at the dietary Met/Lys ratio of 0.37 . These results indicated that maternal plasma $\mathrm{H}_{2} \mathrm{~S}$ concentration could be affected by the dietary Met/Lys ratio.

\subsection{Maternal Plasma $\mathrm{H}_{2} \mathrm{~S}$ Concentration Was Positively Correlated with the Sows' Reproductive Performance}

To determine the involvement of $\mathrm{H}_{2} \mathrm{~S}$ in the reproductive performance of the sows, we analyzed the correlation between the maternal plasma $\mathrm{H}_{2} \mathrm{~S}$ concentration and the number of piglets born alive, the litter weight, and average pig birth weight at E114 d. We found that the maternal plasma $\mathrm{H}_{2} \mathrm{~S}$ concentration had a positive correlation with the number of piglets born alive and the litter weight, 
as shown in Figure 4A,B. However, there was no correlation with the average pig birth weight, as shown in Figure 4C. These data suggested that maternal plasma $\mathrm{H}_{2} \mathrm{~S}$ may have played an important role in the sows' reproductive performance.

\subsection{The Gestational Dietary Met/Lys Ratio Affected Placental $\mathrm{H}_{2} \mathrm{~S}$ Concentration}

We further examined the effect of the gestation dietary Met/Lys ratio on the placental $\mathrm{H}_{2} \mathrm{~S}$ concentration. The placenta was selected based on the average pig birth weight \pm one standard deviation of each group. Similar to the maternal plasma, the placental $\mathrm{H}_{2} \mathrm{~S}$ concentration also changed quadratically with the dietary Met/Lys ratio, as shown in Figure 2. According to the quadratic polynomial regression equation $\left(\mathrm{y}=-139.4 \mathrm{x}^{2}+105.6 \mathrm{x}-9.17, \mathrm{R}^{2}=0.12, p=0.03\right)$, the maximum placental $\mathrm{H}_{2} \mathrm{~S}$ concentration was at the dietary Met/Lys ratio of 0.37 .

\subsection{The $\mathrm{H}_{2} \mathrm{~S}$ Productionof Met Treatment Affected PIEC Cells}

To further confirm the effect of Met on $\mathrm{H}_{2} \mathrm{~S}$ production in vitro, PIEC cells were treated with variable mediums which were (1) Met-free $(0 \mu \mathrm{M}),(2)$ had a physiological concentration of Met $(50 \mu \mathrm{M})$, and (3) had a high concentration of Met $(200,500$, and $1000 \mu \mathrm{M})$, respectively. We found that the $\mathrm{H}_{2} \mathrm{~S}$ concentration was highest in the Met-free medium condition and lowest in a physiological concentration of Met $(50 \mu \mathrm{M})$, as shown in Figure 3. Subsequently, with an increase in Met concentration, the $\mathrm{H}_{2} \mathrm{~S}$ production increased initially (from 50 to $500 \mu \mathrm{M}$ ) and then maintained relative stability (from 500 to $1000 \mu \mathrm{M})$.

\section{Discussion}

$\mathrm{H}_{2} \mathrm{~S}$ is an endogenous stimulator of angiogenesis that promotes vascular endothelial cell proliferation, migration, and angiogenesis by activating the NO/cGMP pathway, opening $\mathrm{K}_{\mathrm{ATP}}$ channels, and promoting the phosphorylation of PI3K/AKT and MAPK pathways $[7,18,19]$. In the present study, we found that the maternal plasma $\mathrm{H}_{2} \mathrm{~S}$ concentration was positively correlated with the sows' reproductive performance. With an increase in Met/Lys ratio in the sows' diet, the maternal plasma and the placental $\mathrm{H}_{2} \mathrm{~S}$ concentrations changed quadratically. These results indicated that there was a dose-effect of Met concentration on $\mathrm{H}_{2} \mathrm{~S}$ production.

Although Met is a precursor for $\mathrm{H}_{2} \mathrm{~S}$ production, recent studies have found that dietary restriction ( $50 \%$ restriction) or Met restriction is the most effective way to increase $\mathrm{H}_{2} \mathrm{~S}$ production. Studies have found that limiting the feed intake can increase liver CGL expression, increase endogenous $\mathrm{H}_{2} \mathrm{~S}$ production, and alleviate liver ischemia-reperfusion injury [11]. Additionally, Met restriction also promotes vascular regeneration and recovery after rodent femoral artery ligation [20] and maintains capillary density in skeletal muscle [21]. Recently, two important studies have further confirmed that by restricting the sulfur amino acid, $\mathrm{H}_{2} \mathrm{~S}$ production can increase in the skeletal muscles by up-regulating the GCN2/ATF4 pathway and activating NAD+/SIRT1 signaling, thus triggering skeletal muscle angiogenesis and delaying muscle aging [22,23]. We found similar results in our study, where medium $\mathrm{H}_{2} \mathrm{~S}$ concentrations were highest under Met-free conditions $(0 \mu \mathrm{M})$, whereas relative to physiological concentrations, high concentrations of Met did not significantly inhibit $\mathrm{H}_{2} \mathrm{~S}$ production in PIEC cells, which suggested that there were some differences between in vitro and in vivo experiments.

In modern animal production, gestational restriction feeding is an effective and widely used practice to improve the reproductive performance of sows. Our previous study found that under the restriction feeding conditions, increasing the Met/Lys ratio from 0.27 to 0.37 can significantly increase the average pig birth weight and the litter weight in the pigs that are born alive [6]. However, when Met/Lys ratio was further increased to 0.47 , the rate of piglets with a weight $<0.9 \mathrm{~kg}$ increased and the placental vascular density decreased significantly [6]. In this study, the maternal plasma at E114 $\mathrm{d}$ and the placental $\mathrm{H}_{2} \mathrm{~S}$ concentrations were consistent with the sows' reproductive performance. The decrease in $\mathrm{H}_{2} \mathrm{~S}$ production caused by an increase in dietary Met was likely to be the cause for the increase in the rate of low birth weight, along with the failure to further improve the reproductive performance 
of the sows. Studies of rodents have found that a high concentration of Met can significantly inhibit CGL activity in peritoneal macrophages, reducing serum $\mathrm{H}_{2} \mathrm{~S}$ content and increasing inflammatory reactions [16]. A recent study showed that exogenous $\mathrm{H}_{2} \mathrm{~S}$ could promote mammary epithelial cell proliferation by activating the PI3K/Akt-mTOR pathway in porcine [24]. Therefore, determination of the appropriate dietary Met content is important for improving the reproductive performance of sows. Meanwhile, increasing the activity of maternal and placenta $\mathrm{H}_{2} \mathrm{~S}$ producing enzymes, or increasing the $\mathrm{H}_{2} \mathrm{~S}$ content by using $\mathrm{H}_{2} \mathrm{~S}$ donors, may be an effective way to alleviate the adverse effects of high Met production. Our current results found that $\mathrm{H}_{2} \mathrm{~S}$ donors diallyl trisufide(DATs) could significantly promote PIEC angiogenesis (unpublished data), which suggests that $\mathrm{H}_{2} \mathrm{~S}$ is a potential target for improving the reproductive performance of sows.

\section{Conclusions}

In conclusion, our findings revealed that gestational dietary Met could affect maternal and placental $\mathrm{H}_{2} \mathrm{~S}$ concentration, which may be an important molecular mechanism affecting placental angiogenesis and piglet development.

Supplementary Materials: The following are available online at http://www.mdpi.com/2076-2615/10/2/251/s1, Table S1: Ingredients and nutrient compositions of the experimental diets.

Author Contributions: J.P. (Jie Peng) designed and carried out experimental work, wrote the manuscript and revised the manuscript. M.X.--acquisition and analysis of data and carried out experimental work. Y.Z. designed the work and analysis of data. J.X.; C.C. and N.H. carried out experimental work. H.W. designed the work and analysis of data. J.P. (Jian Peng) designed the work and revised the manuscript. All authors have read and agreed to the published version of the manuscript.

Funding: The work was supported by the National key Research and Development project of China (2017YFD0502004); Hubei Provincial Creative Team Project of Agricultural Science and Technology (2007-620); China Agriculture Research System (CARS-36).

Conflicts of Interest: The authors declare no conflict of interest. The funders had no role in the design of the study; in the collection, analyses, or interpretation of data; in the writing of the manuscript; or in the decision to publish the results.

\section{References}

1. Gaines, A.M.; Yi, G.F.; Ratliff, B.W.; Srichana, P.; Kendall, D.C.; Allee, G.L.; Knight, C.D.; Perryman, K.R. Estimation of the ideal ratio of true ileal digestible sulfur amino acids:lysine in 8- to 26-kg nursery pigs. J. Anim. Sci. 2005, 83, 2527-2534. [CrossRef]

2. Rees, W.D.; Wilson, F.A.; Maloney, C.A. Sulfur amino acid metabolism in pregnancy: The impact of methionine in the maternal diet. J. Nutr. 2006, 136, 1701S-1705S. [CrossRef] [PubMed]

3. Kalhan, S.C.; Marczewski, S.E. Methionine, homocysteine, one carbon metabolism and fetal growth. Rev. Endocr. Metab. Disord. 2012, 13, 109-119. [CrossRef]

4. Kalhan, S.C. One Carbon Metabolism, Fetal Growth and Long Term Consequences; Nestlé Nutr Inst Workshop Ser.; Nestec Ltd.: Basel, Switzerland, 2013; pp. 127-138.

5. Wu, G.; Bazer, F.W.; Johnson, G.A.; Herring, C.; Seo, H.; Dai, Z.; Wang, J.; Wu, Z.; Wang, X. Functional amino acids in the development of the pig placenta. Reprod. Dev. 2017, 84, 870-882. [CrossRef]

6. Xia, M.; Pan, Y.; Guo, L.L.; Wei, X.X.; Xiong, J.; Wang, L.; Peng, J.; Wang, C.; Peng, J.; Wei, H.K. Effect of gestation dietary methionine/lysine ratio on placental angiogenesis and reproductive performance of sows. J. Anim. Sci. 2019, 97, 3487-3497. [CrossRef]

7. Papapetropoulos, A.; Pyriochou, A.; Altaany, Z.; Yang, G.; Marazioti, A.; Zhou, Z.; Jeschke, M.G.; Branski, L.K.; Herndon, D.N.; Wang, R. Hydrogen sulfide is an endogenous stimulator of angiogenesis. Proc. Natl. Acad. Sci. USA 2009, 106, 21972-21977. [CrossRef]

8. Szabo, C. Hydrogen sulphide and its therapeutic potential. Nat. Rev. Drug Discov. 2007, 6, 917-935. [CrossRef]

9. Li, L.; Rose, P.; Moore, P.K. Hydrogen Sulfide and Cell Signaling. Annu. Rev. Pharmacol. 2011, 51, $169-187$. [CrossRef] 
10. Kabil, O.; Banerjee, R. Redox Biochemistry of Hydrogen Sulfide. J. Biol. Chem. 2010, 285, $21903-21907$. [CrossRef] [PubMed]

11. Hine, C.; Harputlugil, E.; Zhang, Y.; Ruckenstuhl, C.; Lee, B.C.; Brace, L.E.; Longchamp, A.; Trevinovillarreal, J.H.; Mejia, P.; Ozaki, C.K. Endogenous Hydrogen Sulfide Production Is Essential for Dietary Restriction Benefits. Cell 2015, 160, 132-144. [CrossRef] [PubMed]

12. Lu, L.; Kingdom, J.; Burton, G.J.; Cindrovadavies, T. Placental Stem Villus Arterial Remodeling Associated with Reduced Hydrogen Sulfide Synthesis Contributes to Human Fetal Growth Restriction. Am. J. Pathol. 2017, 187, 908-920. [CrossRef] [PubMed]

13. Holwerda, K.M.; Bos, E.M.; Rajakumar, A.; Risstalpers, C.; Van Pampus, M.G.; Timmer, A.; Erwich, J.; Faas, M.M.; Goor, V.H.; Lely, A. Hydrogen sulfide producing enzymes in pregnancy and preeclampsia. Placenta 2012, 33, 518-521. [CrossRef] [PubMed]

14. Wang, K.; Ahmad, S.; Cai, M.; Rennie, J.; Fujisawa, T.; Crispi, F.; Baily, J.; Miller, M.R.; Cudmore, M.J.; Hadoke, P.W.F. Dysregulation of Hydrogen Sulfide Producing Enzyme Cystathionine $\gamma$-lyase Contributes to Maternal Hypertension and Placental Abnormalities in Preeclampsia. Circulation 2013, 127, 2514-2522. [CrossRef] [PubMed]

15. Chen, D.-B.; Feng, L.; Hodges, J.K.; Lechuga, T.J.; Zhang, H. Human trophoblast-derived hydrogen sulfide stimulates placental artery endothelial cell angiogenesis. Biol. Reprod. 2017, 97, 478-489. [CrossRef] [PubMed]

16. Li, J.J.; Li, Q.; Du, H.P.; Wang, Y.L.; You, S.J.; Wang, F.; Xu, X.S.; Cheng, J.; Cao, Y.J.; Liu, C.F.; et al. Homocysteine Triggers Inflammatory Responses in Macrophages through Inhibiting CSE-H2S Signaling via DNA Hypermethylation of CSE Promoter. Int. J. Mol. Sci. 2015, 16, 12560-12577. [CrossRef] [PubMed]

17. Manna, P.; Gungor, N.; McVie, R.; Jain, S.K. Decreased cystathionine-gamma-lyase (CSE) activity in livers of type 1 diabetic rats and peripheral blood mononuclear cells (PBMC) of type 1 diabetic patients. J. Biol. Chem. 2014, 289, 11767-11778. [CrossRef]

18. Kanagy, N.L.; Szabo, C.; Papapetropoulos, A. Vascular Biology of Hydrogen Sulfide. Am. J. Physiol. Cell Physiol. 2017, 312, C537-C549. [CrossRef]

19. Powell, C.R.; Dillon, K.M.; Matson, J.B. A Review of Hydrogen Sulfide $\left(\mathrm{H}_{2} \mathrm{~S}\right)$ Donors: Chemistry and Potential Therapeutic Applications. Biochem. Pharmacol. 2017, 149, 110-123. [CrossRef]

20. Kondo, M.; Shibata, R.; Miura, R.; Shimano, M.; Kondo, K.; Li, P.; Ohashi, T.; Kihara, S.; Maeda, N.; Walsh, K. Caloric Restriction Stimulates Revascularization in Response to Ischemia via Adiponectin-mediated Activation of Endothelial Nitric-oxide Synthase. J. Biol. Chem. 2009, 284, 1718-1724. [CrossRef]

21. Omodei, D.; Fontana, L. Calorie restriction and prevention of age-associated chronic disease. FEBS Lett. 2011, 585, 1537-1542. [CrossRef]

22. Longchamp, A.; Mirabella, T.; Arduini, A.; Macarthur, M.R.; Das, A.; Trevinovillarreal, J.H.; Hine, C.; Bensahra, I.; Knudsen, N.H.; Brace, L.E. Amino Acid Restriction Triggers Angiogenesis via GCN2/ATF4 Regulation of VEGF and H2S Production. Cell 2018, 173, 117-129. [CrossRef] [PubMed]

23. Das, A.; Huang, G.X.; Bonkowski, M.S.; Longchamp, A.; Li, C.; Schultz, M.B.; Kim, L.J.; Osborne, B.; Joshi, S.; $\mathrm{Lu}, \mathrm{Y}$; ; et al. Impairment of an Endothelial NAD(+)-H2S Signaling Network Is a Reversible Cause of Vascular Aging. Cell 2018, 173, 74-89. [CrossRef] [PubMed]

24. Zhang, J.; Ye, J.; Yuan, C.; Fu, Q.; Zhang, F.; Zhu, X.; Wang, L.; Gao, P.; Shu, G.; Jiang, Q. Exogenous H 2 S exerts biphasic effects on porcine mammary epithelial cells proliferation through PI3K/Akt-mTOR signaling pathway. J. Cell. Physiol. 2018, 233, 7071-7081. [CrossRef]

(C) 2020 by the authors. Licensee MDPI, Basel, Switzerland. This article is an open access article distributed under the terms and conditions of the Creative Commons Attribution (CC BY) license (http://creativecommons.org/licenses/by/4.0/). 